J. Lake Sci. (湖泊科学) , 2011, 23(2): 163-173

http: //www. jlakes. org. E-mail : jlakes@niglas.ac.cn

(c) 2011 by Journal of Lake Sciences

\title{
长江输出溶解态无机磷的通量模型灵敏度分析及情景预测”
}

\author{
李新艳 ${ }^{1,2}$, 杨 $^{\text {丽标 }}{ }^{1}$, , 晏维金 $^{1 * *}$ \\ (1:中国科学院地理科学与资源研究所, 北京 100101) \\ (2: 中国科学院南京地理与湖泊研究所湖泊与环境国家重点实验室,南京 210008)
}

\begin{abstract}
摘 要: 研究河流向河口及沿海海域输送的物质通量是一项国际性前沿课题. 基于人类活动影响流域营养盐输移的定量 分析, 应用 Global NEWS 模型模拟 1970-2003 年长江输出溶解态无机磷 (DIP) 的通量, 对其不同来源的贡献率进行了分 析, 并基于千年生态系统评估对未来社会经济发展规划的情景, 对 2050 年长江输出 DIP 的通量进行预测. 结果表明, 从 $1970-2003$ 年, 长江输出的 DIP 通量呈逐年增加的趋势, 2003 年达到了 $14.05 \mathrm{~kg} / \mathrm{km}^{2}$, 比 1970 年 $\left(2.45 \mathrm{~kg} / \mathrm{km}^{2}\right)$ 增加了近 5 倍. 模拟值与对应年份的实测值之间无显著性差异, 平均模拟误差为 $12.29 \% .1993$ 年之前, 长江输出 DIP 的主要来源 是污水, 贡献率达到了 $50 \%$ 以上; 1993 年以后, 以来自非点源的磷输人为主, 其中以磷肥施用的贡献率最高, 且呈逐年增 加的趋势, 2003 年增加到了 $50.30 \%$; 畜禽粪便磷的贡献率变化平稳, 大约在 $22.87 \%$. 污水来源的磷的贡献率自 1993 年 之后呈逐年递减的趋势, 到 2003 年减少为 $24.81 \%$. 情景预测表明, 2050 年无论何种情景下, 长江输出的 DIP 通量都将超 过 2000 年的 2 倍多, 但是不同情景下 DIP 输出通量增加的幅度及不同来源的贡献率有较大差别. 在日益增强的人类活动 影响下,如何控制非点源的磷输入仍将是一项长期而紧迫的任务.
\end{abstract}

关键词: 溶解态无机磷; 输出通量;模型; 长江; 人类活动; 灵敏度分析

\section{Scenario prediction and sensitivity of modeling dissolved inorganic phosphorous export from the Yangtze River}

\author{
LI Xinyan ${ }^{1,2}$, YANG Libiao ${ }^{1} \&$ YAN Weijin ${ }^{1}$ \\ ( 1 : Institute of Geographic Sciences and Natural Resources Research, CAS, Beijing 100101, P. R. China) \\ (2: State Key Laboratory of Lake Science and Environments, Nanjing Institute of Geography and Limnology, CAS, Nanjing \\ 210008, P. R. China)
}

\begin{abstract}
Riverine transport is the principal pathway of dissolved elements from land to the sea. Based on the quantitative analysis of human effects on the phosphorus cycling within the Yangtze River basin, we estimated the exports of dissolved inorganic phosphorous (DIP) from the Yangtze River to the estuary for the period 1970-2003, by using the Global NEWS-DIP model. Modeled DIP export increased from $2.45 \mathrm{~kg} / \mathrm{km}^{2}$ in 1970 to $14.05 \mathrm{~kg} / \mathrm{km}^{2}$ in 2003 under the enhancing anthropogenic activities. No significant difference between the modeled and measured values at the level of $P=0.05$ is observed, and the average model error is 12. 29\% . Diffuse sources (including chemical fertilizer application and animal manure P input) had contributed the most in DIP export since 1993. The contribution varied between $58.60 \%$ and $75.48 \%$. Sewage discharge was the major source of river DIP export before 1993 , with the contribution varying between $99.98 \%$ and $45.21 \%$, while the contribution decreased rapidly since then until to $24.81 \%$ in 2003. We also discussed possible future trajectories of DIP export based on the MEA scenarios. How to control the diffuse nutrient inputs under enhancing human pressures will be a long-term and urgent task.
\end{abstract}

Keywords: DIP; export; model; Yangtze River; human activities; sensitivity analysis

河流物质通量研究是地球科学领域的国际性前沿课题 ${ }^{[1]}$. 国际地圈-生物圈计划 ( IGBP) 中两个核心计

* 国家自然科学基金项目 (20777073) 和江苏省科技厅 “太湖水污染治理专项”项目 (BK2007747) 联合资助. 2010 $03-25$ 收稿;2010-08-16 收修改稿. 李新艳,女, 1978 年生, 博士, 助理研究员;E-mail:xyli@ niglas. ac. cn.

** 通讯作者; E-mail: yanwj@ igsnrr. ac. cn. 
划一海岸带陆海相互作用 (LOICZ) 和全球海洋通量联合研究 (JGOFS) 把通过河流向河口及沿岸海洋输送的 物质通量作为其首要行动的基本目标 ${ }^{[2]}$. 在过去的 50 年里, 世界人口、食物生产和能源消费分别增加了大 约 2.50 倍、3.00 倍和 5.00 倍, 这些巨大变化导致生物可利用营养盐诸如氮、磷 (N、P) 等在陆地上和水循环 中的浓度及输人海洋的数量发生了很大的变化 ${ }^{[3.4]} . \mathrm{N}$ 和 $\mathrm{P}$ 的大量增加引起河口和近海水域富营养化、水体 缺氧、进而引起物种多样性减少和生物栖息地的丧失、渔业资源损失及有害藻类暴发, 上述现象已经成为全 球范围内重要的环境问题 ${ }^{[5-7]}$. 从 2000 年以来, 我国近海发生赤潮的次数和面积显著增加, 特别以东海赤潮 发生状况最为严重. 长江作为连接陆地和海洋的重要通道, 其向东海输送了大量营养物质, 并对河口、近海 生物地球化学过程产生了重要的影响. 研究长江向河口输出营养盐通量的时空变化规律对于有效控制河口 和沿海水体富营养化具有重要意义.

从 $\mathrm{N} / \mathrm{P}$ 比值上看, $\mathrm{P}$ 是中国长江口及邻近海域中生物生命活动的限制性因子 ${ }^{[9-11]}$. 在长江输出到河口和 近海的总磷中, 尽管溶解态无机磷 (DIP) 只占很小的比例, 但是, 它很容易被水生植物、藻类和微生物吸收, 因此其浓度与通量的变化对于维持水体生态系统功能具有决定作用 ${ }^{[12]}$. 国内对长江输送营养盐通量 (特别 是磷通量) 进行了许多研究 ${ }^{[9-20]}$. 例如, Duan 等 ${ }^{[12]}$ 估算出从 1998 年 5 月到 1999 年 4 月长江向河口输出了 $192 \times 10^{6} \mathrm{~kg} / \mathrm{a}$ 磷, 其中颗粒态磷占 $87 \%$, DIP 和 DOP 分别占 $6 \%$ 和 $7 \% ; \mathrm{Liu}$ 等 $^{[9]}$ 研究发现从 $1968-1980$ 年, 长江输出磷酸盐的通量呈逐年增加的趋势, 但是 1980 年以来没有表现出规律性的变化趋势, 并认为河水中 的营养盐浓度与流量、悬浮泥沙和人类活动等因素有关; Yao 等 ${ }^{[17]}$ 研究发现, 从 1967-2006 年, 长江水体中 的 DIP 含量增加与化肥施用量的增加有关, 二者之间存在线性正相关关系; Huang 等 ${ }^{[18]}$ 研究也表明人类经 济活动是导致长江人海的磷通量增加的重要原因. 但是, 这些研究都是以平均浓度和径流量的乘积作为营 养盐通量的估算方法, 而这种方法只是 “记录”了一定时期内特定断面的营养盐输送通量, 很难准确反映人 类活动对于营养盐输移的影响机制. 国外学者通过模型模拟的形式对河流输送营养盐通量进行了大量的研 究 ${ }^{[3,5,21-26]}$, 例如, Caraco 等 ${ }^{[24]}$ 利用 32 个河流系统的城市人口密度 (人/ $\mathrm{km}^{2}$ )、磷肥施用率 $(\mathrm{kg} / \mathrm{ha}$ 耕地面积) 和径流量 $\left(\mathrm{m}^{3} / \mathrm{a}\right)$ 数据作为解释变量, 将这些变量与 DIP 输出通量之间进行统计回归分析, 发现存在显著的 线性相关关系, 在此基础上, 开发了 DIP 输出通量模型, 但是该模型不适用于长江流域, 其模拟结果远高于 实际输出量; Seitzinger \& Kroez $\mathrm{e}^{[3]}$ 基于氮的输人源和汇开发了河流 DIN 输出通量模型, 但是没有考虑生物 固氮和畜禽排泄这两个重要的氮输人源; Harrison 等 ${ }^{[25]}$ 在 Caraco 等 ${ }^{[24]}$ 工作的基础上,利用点源、非点源 $\mathrm{P}$ 输 人、自然界来源 $\mathrm{P}$ 、水库截留和人类用水等作为解释变量, 模拟研究了 1995 年全球河流输出 DIP 的通量. 但 是由于单个流域在地理位置、面积大小、土地利用方式、气候、地质和生态系统方面存在差异 ${ }^{[23]}$, 模型的适用 性还有待验证. Global NEWS 模型 (Global Nutrient Export from Watersheds) 是由联合国教科文组织政府间协 作委员会工作组于 2002 年研发的全球流域营养盐输出模型, 广泛用于研究人类活动与沿海水体富营养化 之间的关系 ${ }^{[26]}$. 该模型综合考虑了流域内自然来源和人类活动来源的营养盐的输人、输出及其在河道输移 中的截留损失. 本研究基于对人类活动影响河流中营养盐输移的定量分析, 应用 Global NEWS 模型研究了 $1970-2003$ 年中国长江向河口输出溶解态无机磷的通量变化, 对其不同来源的贡献率进行了分析, 并基于 千年生态系统评估 (Millenium Ecosystem Assessment, MEA) 对未来社会经济发展规划的情景, 对 2050 年长 江输出 DIP 的通量及其来源进行了预测. 本研究可为有效控制源头污染和沿海水体富营养化提供理论 依据.

\section{1 材料与方法}

\section{1 数据来源}

1.1 .1 社会经济参数 工业污水排放量、生活污水排放量数据来源于中国统计年鉴 ${ }^{[27]}$ 和长江流域内各省份 统计年鉴 ${ }^{[2841]}$; 各省的人均 GDP 和人口密度数据来自各省统计年鉴 ${ }^{[2841]}$.

1.1 .2 非点源输入参数 各省的磷肥施用量、不同类型的畜禽数量和农作物的产量数据均来源于《中国农业 年鉴》 $(1980-2003 \text { 年 })^{[42]}$; 不同畜禽的排泄系数取值参考已发表文献 ${ }^{[43-44]}$; 以上各省的统计数据都乘以各 省在长江流域内的面积比例 ${ }^{[45]}$, 缺失年份的数据用移动平均插值法补齐.

1.1 .3 水文参数 长江流域每年的调水量、灌溉用水和生活用水数据来源于《中国水资源公报》(1997-2003 
年 $)^{[46]}$ 与《长江年鉴》 $(1993-2003 \text { 年 })^{[47]}$; 水库参数来自长江水利网 ${ }^{[48]}$ 和《长江年鉴》 ${ }^{[47]}$ 等; 实测的径流量 和 DIP 浓度数据来自大通站水文监测数据 $(1970-1984$ 年); 采用 SPSS 统计软件对模拟结果进行统计分析.

\section{2 模型介绍与参数计算}

\subsubsection{Global NEWS 模型 本研究所用的 Global NEWS-DIP 模型是指 ${ }^{[23]}$ :}

$$
D I P_{\text {yield }}=\left(1-Q_{\text {rem }}\right) \cdot\left(1-D_{\text {dip }}\right) \cdot\left(D I P_{\text {sew }}+F E_{\mathrm{ws}} \cdot T P_{\text {diff }}\right)
$$

式中, DIP $P_{\text {yield }}$ 为 NEWS-DIP 模型估算的 DIP 输出通量 $\left(\mathrm{kg} /\left(\mathrm{km}^{2} \cdot \mathrm{a}\right)\right) ; D I P_{\mathrm{sew}}$ 为点源污水排放进人河流的 DIP 通量 $\left(\mathrm{kg} /\left(\mathrm{km}^{2} \cdot \mathrm{a}\right)\right) ; F E_{\mathrm{ws}}$ 为指径流流失率, 等于从陆地汇人河流的 DIP 占 TP 的比例 $(0-100 \%) ; T P_{\text {diff }}$ 为 来自非点源的 TP 输人通量 $\left(\mathrm{kg} /\left(\mathrm{km}^{2} \cdot \mathrm{a}\right)\right) ; Q_{\mathrm{rem}}$ 是 DIP 输出通量中引水调水带走的比例 $(0-100 \%) ; D_{\mathrm{dip}}$ 是 被水库截留的 DIP 比例 $(0-100 \%)$.

1.2 .2 来自污水的 DIP 输入通量 流域内污水中磷的主要来源是工业污水和生活污水的排放. 首先统计中 国长江流域内各省份从 1970-2003 年排放的工业污水量和生活污水量, 工业污水中磷的平均浓度 $\left(P_{\mathrm{ci}}\right)$ 取 $3 \mathrm{mg} / \mathrm{L}$, 生活污水中磷的平均浓度 $\left(P_{\mathrm{cd}}\right)$ 取 $11 \mathrm{mg} / \mathrm{L}^{[49]}$. 再利用下面的公式计算得到污水中的 DIP 输人通量.

$$
\begin{gathered}
D I P_{\mathrm{sew}}=a \cdot\left(T P_{\text {ind }} \times P_{\mathrm{ci}}+T P_{\mathrm{dom}} \times P_{\text {cd }}\right) \times(1-R) / A \\
a=0.485+(R / 0.8) \times 0.255^{[19]}
\end{gathered}
$$

式中, DIP $P_{\mathrm{sew}}$ 为来自污水的 DIP 输人通量 $\left(\mathrm{kg} /\left(\mathrm{km}^{2} \cdot \mathrm{a}\right)\right)$; 小写字母 $a$ 是校正系数, 等于污水中 DIP 占 TP 的 比例 $(0-100 \%) . T P_{\mathrm{ind}}$ 为工业污水排放量 $(\mathrm{kg}) ; P_{\mathrm{ci}}$ 为工业污水中的总磷平均浓度 $(\mathrm{mg} / \mathrm{L}) ; T P_{\mathrm{dom}}$ 为生活污水 排放量 $(\mathrm{kg}) ; P_{\mathrm{cd}}$ 为生活污水中的总磷平均浓度 $(\mathrm{mg} / \mathrm{L}) ; R$ 为污水处理设施对磷的去除率 $(0-100 \%) ; A$ 为 大通站控制的流域面积 $\left(\mathrm{km}^{2}\right)$.

我国污水处理类型主要有 3 种, 其中机械处理占 $85 \%$, 磷去除率为 $20 \%$; 生物处理占 $15 \%$, 磷去除率为 $23 \%$; 高级处理的磷去除率为 $80 \%{ }^{[50-51]}$, 我国目前没有高级处理. 首先统计中国从 $1970-2003$ 年的污水处 理率 $r$ (利用网络资源得到), 用 $r$ 乘以这三种处理方式所占的比例及相应的磷去除率,得到我国 1970-2003 年的污水处理设施磷去除率, 即 $R=0.20 r$.

1.2.3 非点源 DIP 输入通量计算 非点源磷的人为输人源包括磷肥施用 $\left(T P_{\mathrm{fe}}\right)$ 和动物粪便施用 $\left(T P_{\mathrm{ma}}\right)$. 输 出部分指农作物收获输出的磷通量 $\left(T P_{\text {exp }}\right)$. 根据公式:

$$
T P_{\text {diff }}=k_{1} T P_{\mathrm{fe}}+k_{2} T P_{\text {ma }}-T P_{\text {exp }}
$$

式中, $T P_{\text {diff }}$ 是指每年通过非点源释放到河流中的总磷通量 $\left(\mathrm{kg} /\left(\mathrm{km}^{2} \cdot \mathrm{a}\right)\right) ; T P_{\mathrm{fe}}$ 是化肥磷输人通量 $\left(\mathrm{kg} /\left(\mathrm{km}^{2} \cdot \mathrm{a}\right)\right) ; T P_{\text {ma }}$ 是牲畜粪便磷输人通量 $\left(\mathrm{kg} /\left(\mathrm{km}^{2} \cdot \mathrm{a}\right)\right) ; T P_{\text {exp }}$ 是农作物收获输出的磷通量 $\left(\mathrm{kg} /\left(\mathrm{km}^{2} \cdot \mathrm{a}\right)\right) ; k_{1} 、 k_{2}$ 分别为校正系数 $(0-100 \%)$.

(1) $T P_{\mathrm{fe}}$ 的计算: $T P_{\mathrm{fe}}$ 等于长江流域内全部省份的每年磷肥施用量除以大通站控制的流域面积. 磷肥的 作物利用率很低, 累计平均利用率为 $12 \%-19 \%$, 在土壤中累积的磷肥磷的比例为 $81 \%-88 \%{ }^{[52]}$, 本研究中 取其平均值 $84.50 \%$, 所以, 对磷肥施用率的校正系数 $k_{1}$ 取 0.845 . 磷肥 (折纯) 施用量数据来源于《中国农业 年鉴》 $(1980-2003 \text { 年 })^{[42]}$, 数据缺乏的年份通过移动平均插值的方法得到.

(2) $T P_{\mathrm{ma}}$ 的计算: $T P_{\mathrm{ma}}$ 等于长江流域内全部省份的每年畜禽粪便磷排放量除以大通站控制的流域面积. 畜禽粪便磷排放量等于畜禽数量乘以各种畜禽的排泄系数 (表 1$)^{[43-44]}$. 畜禽 $($ 包括猪、牛、羊、马、家禽) 数量 包括存栏量和出栏量,数据来源于《中国农业年鉴》(1980-2003 年) ${ }^{[42]}$.

有机肥磷的累计平均利用率为 $49.00 \%-51.50 \%{ }^{[52]}$, 在土壤中累积的有机肥磷所占比例为 $48.50 \%-$ $51.00 \%$, 本研究中取平均值 $49.70 \%$; 根据上海市土肥站 1989 年对郊区十县 (区) 畜禽粪便资源利用进行的 调查, 从三年定点农户投肥资料看,畜禽粪的实际利用率为 $53.50 \%{ }^{[33]}$, 所以,对禽粪便磷输入通量的校正 系数 $k_{2}$ 取值为 $0.535 \times 0.497=0.27$.

(3) $T P_{\text {exp }}$ 的计算:用长江流域内全部省份的每年农作物产量乘以每种农作物的磷含量后除以大通站控 制的流域面积. 主要农作物种类中的磷含量见表 2. 各省份农作物产量数据来源于《中国农业年鉴》 ${ }^{[42]}$. 
表 1 畜禽排泄系数

Tab. 1 Excretion rates for different types of animals

\begin{tabular}{|c|c|c|c|c|c|}
\hline \multirow{2}{*}{ 畜禽种类 } & \multicolumn{2}{|l|}{ 鲜粪 } & \multicolumn{2}{|l|}{ 鲜尿 } & \multirow{2}{*}{$\begin{array}{c}\text { 产磷量 } \\
(\mathrm{kg} /(\text { 只 }(\text { 头 }) \cdot \mathrm{a}))\end{array}$} \\
\hline & 产量 $(\mathrm{kg} /(\mathrm{d} \cdot$ 只 $($ 头 $)))$ & 磷含量 $(\%)$ & 产量 $(\mathrm{L} /(\mathrm{d} \cdot$ 只 $($ 头 $)))$ & 磷含量 $(\%)$ & \\
\hline 猪 & 3.00 & 0.40 & 3.50 & 0.10 & 5.91 \\
\hline 牛 & 25.00 & 0.25 & 10.00 & 0.03 & 23.91 \\
\hline 羊 & 2.00 & 0.30 & 0.70 & 0.10 & 2.50 \\
\hline 马 & 15.00 & 0.30 & 7.50 & 0.05 & 17.79 \\
\hline 家禽 & 0.10 & 1.54 & & & 0.56 \\
\hline
\end{tabular}

表 2 江流域主要农作物的磷含量

Tab. 2 Content of phosphorus in different types of crops

\begin{tabular}{ccccccccc}
\hline 类型 & 稻谷 & 小麦 & 玉米 & 大豆 & 薯类 & 花生 & 油菜籽 & 棉花 \\
\hline 磷含量 $^{1)}(\%)$ & 0.40 & 0.50 & 0.40 & 1.60 & 1.40 & 1.30 & 0.90 & 4.00 \\
校正系数 & 2.00 & 2.00 & 2.00 & 2.00 & 1.50 & 2.00 & 2.00 & 3.00 \\
\hline
\end{tabular}

1) 籽实中的磷含量, 农作物产量包括根茎和籽实, 统计的产量只有籽实, 所以要用统计的籽实产量乘以校正系数.

(4) 引水调水系数 $Q_{\mathrm{rem}}$ 的计算公式为 ${ }^{[23]}$ :

$$
Q_{\text {rem }}=\left(Q_{\text {div }}+Q_{\text {irr }}\right) / Q_{\text {nat }}
$$

式中, $Q_{\text {div }}$ 是流域内的人类生活用水量和调水量 $\left(\mathrm{km}^{3} / \mathrm{a}\right) ; Q_{\text {irr }}$ 是流域内的农业灌溉用水量 $($ 最终流人河流的 灌溉用水不计算在内 $)\left(\mathrm{km}^{3} / \mathrm{a}\right) ; Q_{\text {nat }}$ 是受人类活动影响前的河流流量 $\left(\mathrm{km}^{3} / \mathrm{a}\right)$. 本研究中 $Q_{\text {nat }}$ 采用长江大通 站 $1950-2000$ 年的平均年径流量, 即 $9051 \times 10^{8} \mathrm{~m}^{3}$.

(5) 水库对磷的截留系数 $D_{\mathrm{dip}}$ 的计算参考水库对氮的截留系数公式 ${ }^{[54]}$ :

$$
D_{\text {dip }}=\frac{1}{Q} \cdot \sum_{i=1}^{n} 0.8845 \cdot\left(\frac{D E P T_{i}}{R T_{i}}\right)^{-0.3677} \cdot Q_{i}
$$

式中, $D E P T_{i}$ 是水库深度 $(\mathrm{m}) ; R T_{i}$ 是滞留时间 $(\mathrm{a}) ; i$ 是流域内的水库数目 $(i=1,2,3, \cdots, n) ; Q_{i}$ 是水库 $i$ 截留 的径流量; $Q$ 是建水库前的径流量.

本研究统计了长江流域内 92 座有效库容大于 $1 \times 10^{6} \mathrm{~m}^{3}$ 的水库, 总库容达 $1004.54 \times 10^{8} \mathrm{~m}^{3}$, 占长江流域 全部库容的 $59.79 \%$, 其中有效库容占总库容的 $42.07 \%{ }^{[47]}$ (截止到 2003 年). 各水库的统计参数包括总库 容 $\left(\mathrm{km}^{3}\right)$ 、有效库容 $\left(\mathrm{km}^{3}\right)$ 、库区多年平均径流量 $\left(\mathrm{km}^{3}\right)$ 、正常蓄水位 $(\mathrm{m})$ 、库区面积 $\left(\mathrm{km}^{2}\right)$ 、建成年份等. 首

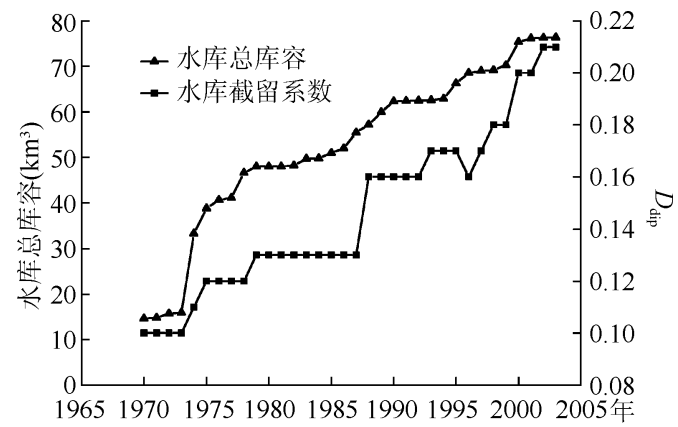

图 1 长江流域水库的截留系数和总库容 的时间序列变化对比

Fig. 1 Time serial changes of retention ratios and total storage of reservoirs in the Yangtze River Basin during $1970-2003$ 先把水库数据根据建成年份排列, 计算该年份之前 (包括该年份) 已建水库对磷的截留系数 $D_{\text {dip }}$, 然后把 该年份之前的所有水库的截留系数相加, 并用统计的 有效库容占总库容的比例进行校正. 鄱阳湖和洞庭湖 属于天然水库, 根据公式 (6) 计算得到两湖的截留系 数分别为 0.04 和 0.05 . 虽然两湖的面积有逐年缩小 的趋势, 但是我们假设在 $1970-2003$ 年间, 两湖的截 留系数不变.

利用 SPSS 统计分析发现, 1970-2003 年间长江 流域内水库的截留系数有逐年增加的趋势 (图 1), 而 且与水库的总库容之间呈显著的线性正相关, Pearson 相关系数 $r=0.92, P<0.01$.

（6）地表径流损失率 $F E_{\mathrm{ws}}$ 的确定: 国内外研究表 
明, 在从陆地进人地表水体的过程中, 磷肥或者有机肥中大约有 $0.10 \%-3.30 \%$ 的磷以 DIP 的形式随地表径 流流失 ${ }^{[55-62]}$. 但是, Harrison 等 $^{[63]}$ 认为, 在径流量较高的流域, 这个结果偏低. 他认为以 DIP 形式随径流的流 失量占总磷的比例 (即 $F E_{\mathrm{ws}}$ ) 范围是 $1.00 \%-10.00 \%$. 基于以上研究结果, 本研究在 $1970-1990$ 年间的 $F E_{\mathrm{ws}}$ 取值为 $5.00 \%$, 与氮的径流流失率相同 ${ }^{[64]}$; 由于我国在 1989 年启动了长江中上游防护林体系建设工程, 水 土保持效应增强 ${ }^{[65]}$, 假设防护林工程在 1991 年发挥效益, 则 DIP 的径流损失率会有所降低,对 1991-2003 年的径流损失率 $F E_{\mathrm{ws}}$ 取值为 $2.50 \%$.

\section{3 不同来源的贡献率计算}

1.3.1 污水贡献率 污水排放对长江输出 DIP 通量的贡献率计算公式为 ${ }^{[23]}$ :

$$
D I P_{\text {sew }} \%=D I P_{\text {sew }} \cdot F E_{\text {riv }} \cdot 100 / D I P_{\text {yield }}
$$

式中, $D I P_{\mathrm{sew}} \%$ 是污水贡献率 $(\%) ; F E_{\mathrm{riv}}$ 是河流截留系数 $(0-100 \%) ; F E_{\mathrm{riv}}=\left(1-Q_{\mathrm{rem}}\right) \cdot\left(1-D_{\mathrm{dip}}\right)$.

1.3.2 非点源贡献率 我们分别估算了非点源污染物中的磷肥施用 $\left(T P_{\mathrm{fe}}\right)$ 、畜禽粪便排放 $\left(T P_{\mathrm{ma}}\right)$ 对 DIP 输出通量 的贡献率. 计算方法为用每一种非点源磷的输人通量乘以农作物收获后剩下的比例 $(G, 0-100 \%)^{[23]}$. 公式为:

$$
\begin{aligned}
D I P_{\mathrm{fe}} \% & =F E_{\text {riv }} \cdot F E_{\mathrm{ws}} \cdot k_{1} T P_{\mathrm{fe}} \cdot G \cdot 100 / D I P_{\text {yield }} \\
D I P_{\text {ma }} \% & =F E_{\text {riv }} \cdot F E_{\mathrm{ws}} \cdot k_{2} T P_{\text {ma }} \cdot G \cdot 100 / D I P_{\text {yield }} \\
& G=1-T P_{\text {exp }} /\left(k_{1} T P_{\mathrm{fe}}+k_{2} T P_{\text {ma }}\right)
\end{aligned}
$$

\section{4 实测的 DIP 输出通量}

利用大通站从 $1970-1985$ 年的水文监测数据 (包括径流量 $Q$ 、DIP 浓度 $C$ ) 计算得到实测的 DIP 输出 通量:

$$
D I P_{\mathrm{obs}}=Q C / A
$$

式中, $D I P_{\mathrm{obs}}$ 是实测的 DIP 输出通量 $\left(\mathrm{kg} /\left(\mathrm{km}^{2} \cdot \mathrm{a}\right)\right) ; Q$ 是大通站取水断面的径流量 $\left(\times 10^{10} \mathrm{~m}^{3}\right) ; C$ 是大通站 取水断面的 DIP-P 浓度 $(\mathrm{mg} / \mathrm{L}) ; A$ 是大通站控制的流域面积 $\left(\mathrm{km}^{2}\right)$.

\section{5 模型检验}

采用模拟误差对模拟结果进行检验, 计算公式为:

$$
M E_{i}=100\left(\operatorname{Mod}_{i}-O b s_{i}\right) / O b s_{i}
$$

式中, $M E_{i}$ 是模拟误差 $(\%) ; \operatorname{Mod}_{i}$ 是模拟的 DIP 输出通量 $\left(\mathrm{kg} /\left(\mathrm{km}^{2} \cdot \mathrm{a}\right)\right) ; O b s_{i}$ 是实测的 DIP 输出通量 $\left(\mathrm{kg} /\left(\mathrm{km}^{2} \cdot \mathrm{a}\right)\right)$.

同时,选用 Nash-Suttcliffe 模拟效率系数 $(N S C)$ 评 价模型估算结果, 计算公式为:

$N S C=1-\left[\sum\left(\mathrm{Obs}_{i}-\mathrm{Mod}_{i}\right)^{2} / \sum\left(\mathrm{Obs}_{i}-\overline{\mathrm{Obs}_{i}}\right)^{2}\right]$

式中, $\overline{O b s}$ 是实测的 DIP 输出通量的平均值 $\left(\mathrm{kg} /\left(\mathrm{km}^{2} \cdot \mathrm{a}\right)\right)$.

\section{2 结果与讨论}

\section{1 模拟结果与实测值的对比}

DIP 输出通量 $\left(D I P_{\text {yield }}\right)$ 的模拟值与实测值对比结果

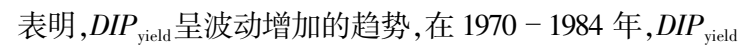
变化很小,平均为 $2.78 \mathrm{~kg} /\left(\mathrm{km}^{2} \cdot \mathrm{a}\right)$; 而在 $1985-2003$ 年, $D I P_{\text {yield }}$ 迅速增加, 2003 年达到了 $14.05 \mathrm{~kg} /\left(\mathrm{km}^{2} \cdot \mathrm{a}\right)$, 比 1970 年增加了近 5 倍 (图 2). 运用 SPSS 软件, 对 $D I P_{\text {yield }}$ 模拟值与对应年份的实测值之间进行差异显著 性检验, 结果显示, 在 $P=0.01$ 水平上, 模拟值与实测

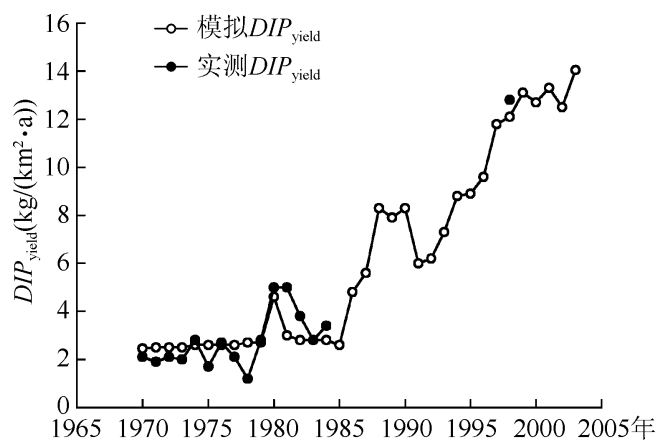

图 2 长江输出 DIP 通量的模拟值与 实测值的时间序列变化 $(1970-2003$ 年)

Fig. 2 Comparison of modeled (solid circle symbols) and measured DIP yields (hollow circle symbols) in the Yangtze River Basin during 1970 - 2003 


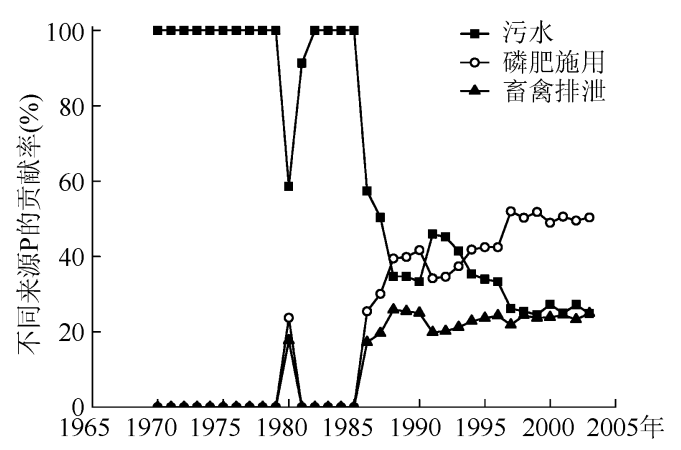

图 $31970-2003$ 年不同类型的磷输人源对 DIP 输出通量的贡献率的时间序列变化

Fig. 3 Time series of different source of phosphorus contributions to DIP yields for the Yangtze River during $1970-2003$
值之间无显著性差异, 表明模拟值比较接近于实测值. $D I P_{\text {yield }}$ 的模拟误差范围为 $-39.58 \%$ 至 $113.53 \%$, 平均 误差为 $12.29 \% .67 \%$ 的 Nash 效率系数 NSC 位于 $0.60-1.00$ 之间,说明模型效率较高.

\section{2 不同来源的贡献率分析}

根据公式 (7)-(10), 计算得到不同来源的 P 输人 对 DIP 输出通量的贡献率, 其时间序列变化可看出 (图 3), 1970-1985 年的 DIP 输出通量中以污水的贡献率 最高, 这段时期非点源污染很少, 污水排放是河水中磷 素的主要来源; 1985 年以来, 污水的贡献率呈逐年下 降的趋势, 1993 年降低到了 $41.40 \%$, 而到了 $1994-$ 2003 年, 污水来源的磷的贡献率低于磷肥施用而居于 第二位, 到了 2003 年下降到 $24.81 \%$; 而磷肥施用的贡 献率逐年增加, 1994 年已经超过了污水的贡献率, 稳 定在 $48.00 \%$ 左右, 成为 DIP 输出通量的主要来源; 在

$1986-2003$ 年间畜禽粪便磷对于 DIP 输出通量的贡献率相对稳定, 在 $22.87 \%$ 左右, 表明畜禽粪便释放将是 一项稳定的磷污染源.

\section{3 模型不确定性分析}

化学磷肥或有机肥施人农田后, 其去向有三: 被作物吸收、通过各种途径而损失、残留于土壤中. 残留于 土壤中的磷可积累于土壤剖面中植物根系活动层以下地下水层以上的部分, 构成对环境的潜在威胁. 这部 分被土壤储存的磷既不能被作物吸收也不随河水流失, 往往被研究人员忽视. 系统储存磷的容量会随着磷 输人量的增加而增加, 然而储存能力并不是无限期增加的, 当流域内的磷输人量持续增加, 以致超出了系统 的容纳能力, 流域储存磷的能力会最终趋向饱和, 称为 “磷饱和度”, 用土壤已经吸附的磷素占储磷容量的比 例表示. 荷兰把土壤磷饱和度为 $25.00 \%$ 作为土壤环境敏感的临界指标 ${ }^{[66]}$. 当土壤中磷的饱和度较低时, 则 磷释放量较低; 但当土壤磷饱和度超过 $25.00 \%$ 时, 致使土壤磷释放潜力大大增加, 大量的磷进人地表水而 增加地表水中的磷浓度 ${ }^{[67]}$. 另外, 在产汇流过程中, 人类通过引水灌溉、挖渠建坝、水土保持工程等也影响到 流域对磷的截留. 模型中的径流损失参数 $F E_{\mathrm{ws}}$ 采用了两个确定的数值 $(5.00 \%$ 和 $2.50 \%)$, 没有表现出时间 变化趋势. 通过地表径流损失的磷素随着时间延长发生怎样的变化趋势? 解决这个问题还需要进行长期而 系统的实地监测工作.

\section{4 敏感性分析}

敏感性分析是指从定量分析的角度研究有 关因素发生某种变化对某一个或一组关键指标 影响程度的一种不确定分析技术, 其实质是通 过逐一改变相关变量数值的方法来解释关键指 标受这些因素变动影响大小的规律,主要采用 敏感系数度量. 敏感系数 $=$ 目标值变动百分比 $/$ 参数值变动百分比. 敏感系数越大, 说明该输人 参数对输出结果的影响越大, 反之, 则影响越 小. 由敏感性分析可知 (表 3), 农作物输出磷量 (磷汇) 变化 $5 \%$,引起模拟 DIP 输出通量的变化 率最大, 敏感系数为 2.46 . 磷肥施用输人通量增 加 $5 \%$ 引起的敏感系数为 -1.64 , 畜禽排泄磷输 人通量增加 5\% 引起的敏感系数为 -1 , 其余因 素的敏感系数绝对值均小于 1. 敏感性分析表明
表 3 敏感性分析: 输人参数增加 $5 \%$ 引起的 模拟 DIP 输出通量变化的敏感系数

Tab. 3 Sensitivity analysis indicating changes in predicted DIP yield as a function of increasing input data sets and model parameters by $+5 \%$

\begin{tabular}{ccc}
\hline \multirow{2}{*}{ 输人源或参数 } & \multicolumn{2}{c}{ 敏感系数 $(\%)$} \\
\cline { 2 - 3 } & 范围 & 平均值 \\
\hline 引水调水系数 $Q_{\mathrm{rem}}$ & $0.15-0.23$ & 0.19 \\
大坝截留系数 $D_{\mathrm{dip}}$ & $0.11-0.27$ & 0.17 \\
河流截留系数 $F E_{\mathrm{riv}}$ & -0.95 & -0.95 \\
磷肥施用 $T P_{\mathrm{fe}}$ & -3.74 至 0 & -1.64 \\
畜禽粪便排放 $T P_{\mathrm{ma}}$ & -2.93 至 0 & -1.00 \\
农作物输出磷量 $T P_{\mathrm{exp}}$ & $0-8.43$ & 2.46 \\
污水来源的磷输人通量 $T P_{\mathrm{sew}}$ & -0.95 至 -0.24 & -0.62 \\
\hline
\end{tabular}


农作物输出磷量是 Global NEWS-DIP 模型的最敏感因素.

\section{5 情景预测}

千年生态系统评估 (Millennium Ecosystem Assessment, MEA) 计划提出了未来社会发展的四种情景, 即 全球协同 (Global Orchestration,GO, 全球协同、经济发展、被动保护环境)、实力秩序 (Order from Strength,OS, 各自为政、经济发展、被动保护环境)、适应拼接 (Adapting Mosaic, AM,适应发展、主动保护环境)、技术乐园 (Techno Garden, TG, 技术革新、主动保护环境), 并对每种情景下的人口、经济、技术及环境状况进行了描述. 本研究基于 MEA 计划, 以 2000 年为对照, 对 2050 年长江输出的 DIP 通量进行了预测.

2.5 .1 参数确定 (1) 径流量 $(Q)$ : 从 1950-2005 年长江径流量呈周期性波动变化, 虽然 20 世纪 90 年代 长江发生了频繁的洪水灾害, 而且在长江流域内建了 4 万多座水库, 也没有改变长江人海径流量平稳的 变化趋势. 未来 50 年内, 全球温室气体排放量继续增加, 全球变暖趋势加剧, 作为对全球变暖的响应, 中 国长江流域的降水量将会增加, 由于长江径流量集中于汛期 (大通站多年汛期径流量占全年的 $71 \%$ ), 所 以,随着夏季降水量的增加, 长江径流量也将有所增加. 在 2000 年 $Q=0.5348 \mathrm{~m} / \mathrm{a}$ (用大通站的年径流量 除以大通站控制的流域面积）的基础上，假设 2050 年 $Q=0.58 \mathrm{~m} / \mathrm{a}$.

（2）引水调水参数 $\left(Q_{\mathrm{rem}}\right): 2000$ 年调水量只有 $68 \times 10^{8} \mathrm{~m}^{3}$, 约占长江年平均径流量的 $0.75 \%$; 三线南水 北调工程建成后, 每年可从长江调水 $660 \times 10^{8} \mathrm{~m}^{3}$ 输往黄淮海流域, 调水量约占长江多年平均径流量的 $7.3 \%$. 假设在 2000 年用水量的基础上, 长江流域以每年增加 $2 \%$ 的水量满足了经济发展的需要, 则 2050 年 的用水量 $F$ 将达 $4416 \times 10^{8} \mathrm{~m}^{3}$, 其中 $1640.8 \times 10^{8} \mathrm{~m}^{3}$ 是 2000 年的用水量,再把用水量乘以农业用水比例 $69 \%$, 得到 2050 年的农业用水量 $3047 \times 10^{8} \mathrm{~m}^{3}$. 根据公式 $Q_{\mathrm{rem}}=$ (农业用水 + 调水)/人类活动影响前的长江 径流量 (取 $1950-2000$ 年长江径流量的平均值 $9051 \times 10^{8} \mathrm{~m}^{3}$ ), 得到 2050 年 $Q_{\mathrm{rem}}$ 取值为 0.41 .

(3) 水库截留参数 $\left(D_{\mathrm{dip}}\right)$ : 到 2050 年, 金沙江和雅砻江的梯级水电站将陆续建成, 长江干流三峡大坝也 投人使用, 库容量达到 $1265 \times 10^{8} \mathrm{~m}^{3}$, 这些水库对河流中 DIP 的截留效应大约为 0.05 , 在 2003 年 $D_{\mathrm{dip}}$ 取值为 0.21 的基础上,设定 2050 年 $D_{\mathrm{dip}}$ 取值为 0.26 .

(4) 污水来源的 DIP 输人通量 $\left(D I P_{\text {sew }}\right)$ 通过下面的方程模拟计算得到:

$$
D I P_{\mathrm{sew}}=a \cdot 0.365 \cdot\left(N_{\mathrm{em}} / 6\right) \cdot H \cdot I \cdot(1-R)
$$

式中, $D I P_{\mathrm{sew}}$ 是污水排放进人河流中的 DIP 通量 $\left(\mathrm{kg} /\left(\mathrm{km}^{2} \cdot \mathrm{a}\right)\right) ; a$ 是校正系数, $a=0.13(0.13$ 为河水中的 $D I P$ 占 $\mathrm{TP}$ 的比例 $\left.{ }^{[12]}\right) . H$ 是人口密度 $\left(\right.$ 人 $\left./ \mathrm{km}^{2}\right) ; I$ 是与污水处理设施有关的人口比例, 本研究中 $I$ 取长江流 域内的城镇人口比例 $(0-100 \%) ; R$ 是污水处理后的磷去除率 $(0-100 \%)$.

$N_{\mathrm{em}}$ 是人均每天排放的总氮 $\left(\mathrm{g} /(\right.$ 人 · 天 $)$ ) ; 根据澳大利亚 27 个污水处理厂的测定结果 ${ }^{[68]}, P_{\mathrm{em}}$ ( 人均每 天排放的总磷) 与 $N_{\mathrm{em}}$ 之间有显著正相关关系, 设定 $P_{\mathrm{em}}=1 / 6 N_{\mathrm{em}}$. 而 $N_{\mathrm{em}}$ 的计算公式为 ${ }^{[69-70]}$ :

$$
N_{\text {em }}=4+14 \cdot(G D P / 33000)^{0.3}
$$

式中, $G D P$ 是流域内基于购买力的人均 $G D P(\$ /$ 人).

(5) 非点源输人参数 $T P_{\mathrm{fe}} 、 T P_{\text {ma }}$ 和 $T P_{\text {exp }}$ :

根据下面的线性回归方程得到 ${ }^{[70]}$ :

$$
\begin{aligned}
& Y_{1}=-3188.55+20.27 \cdot X, R^{2}=0.97, n=34, P<0.01 \\
& Y_{2}=-2489.21+20.07 \cdot X, R^{2}=0.98, n=34, P<0.01 \\
& Y_{3}=-558.43+7.04 \cdot X, R^{2}=0.95, n=34, P<0.01
\end{aligned}
$$

式中, $Y_{1} 、 Y_{2} 、 Y_{3}$ 分别代表 2050 年的 $T P_{\mathrm{fe}} 、 T P_{\text {ma }}$ 和 $T P_{\text {exp }}, X$ 是长江流域内的人口密度 $\left(\right.$ 人 $\left./ \mathrm{km}^{2}\right)$. 长江流域内总 人口在全国总人口中所占的比例在 1970-2003 年间平均为 30\%, 根据国家规划, 2050 年全国人口将控制在 15 亿, 因此,长江流域将有 5 亿人口, 假设 GO、OS、AM、TG 情景下各达到 4.8、5、5、4.9 亿, 除以流域面积 $\left(1705383 \mathrm{~km}^{2}\right)$ 后得到人口密度分别为 $282 、 293 、 293 、 287$ 人 $/ \mathrm{km}^{2}$, 参数取值见表 4 . 
表 42050 年未来社会发展四种情景下的参数取值 (与 2000 年比较)

Tab. 4 Model parameters under four scenarios of future society in 2050 (Comparing to the year of 2000)

\begin{tabular}{|c|c|c|c|c|c|c|}
\hline & \multirow{2}{*}{ 参数 } & \multirow{2}{*}{2000 年 } & \multicolumn{4}{|c|}{2050 年 } \\
\hline & & & GO & OS & $\mathrm{AM}$ & TG \\
\hline \multirow{5}{*}{ 水文参数 } & $Q(\mathrm{~m} / \mathrm{a})$ & 0.53 & 0.58 & 0.58 & 0.58 & 0.58 \\
\hline & $Q_{\text {rem }}$ & 0.22 & 0.41 & 0.41 & 0.41 & 0.41 \\
\hline & $D_{\text {dip }}$ & 0.20 & 0.28 & 0.28 & 0.26 & 0.26 \\
\hline & $F E_{\text {riv }}$ & 0.22 & 0.43 & 0.43 & 0.44 & 0.44 \\
\hline & $F E_{\mathrm{ws}}$ & 0.03 & 0.05 & 0.05 & 0.03 & 0.02 \\
\hline \multirow[t]{4}{*}{ 点源 } & $G D P($ \$ / 人 $)$ & 655 & 104806 & 80283 & 63995 & 65301 \\
\hline & $H\left(\right.$ 人 $\left./ \mathrm{km}^{2}\right)$ & 213 & 282 & 293 & 293 & 287 \\
\hline & $I$ & 0.23 & 0.72 & 0.72 & 0.72 & 0.72 \\
\hline & $R$ & 0.05 & 0.18 & 0.13 & 0.24 & 0.27 \\
\hline \multirow[t]{3}{*}{ 非点源 } & $T N_{\mathrm{fe}}\left(\mathrm{kg} /\left(\mathrm{km}^{2} \cdot \mathrm{a}\right)\right)$ & 3425 & 6462 & 6990 & 6990 & 6726 \\
\hline & $T N_{\text {ma }}\left(\mathrm{kg} /\left(\mathrm{km}^{2} \cdot \mathrm{a}\right)\right)$ & 2971 & 5213 & 5601 & 5601 & 5407 \\
\hline & $T N_{\exp }\left(\mathrm{kg} /\left(\mathrm{km}^{2} \cdot \mathrm{a}\right)\right)$ & 2591 & 4206 & 4462 & 4462 & 4334 \\
\hline
\end{tabular}

2.5.2 情景预测结果 把以上参数代人到公式(1)中, 计算得到四种情景下的 DIP 输出通量, 并与 2000 年作 比较 (图 4a). 与 2000 年相比, 2050 年无论何种情景下, 长江向河口输出的 DIP 通量都超过了 2000 年的水平 2 倍多, 但是 2050 年四种情景下 DIP 通量增加的幅度有所差别. 以 OS 情景下的 DIP 输出通量最高 $\left(58.25 \mathrm{~kg} /\left(\mathrm{km}^{2} \cdot \mathrm{a}\right)\right)$, 其次为 GO 情景 $\left(57.12 \mathrm{~kg} /\left(\mathrm{km}^{2} \cdot \mathrm{a}\right)\right)$, 然后是 AM 情景 $\left(44.02 \mathrm{~kg} /\left(\mathrm{km}^{2} \cdot \mathrm{a}\right)\right)$, TG 情 景下的 DIP 输出通量最低 $\left(33.96 \mathrm{~kg} /\left(\mathrm{km}^{2} \cdot \mathrm{a}\right)\right)$.

根据公式 (8)-(10) 计算得到不同来源磷的贡献率, GO 和 OS 情景下仍以非点源磷输人对 DIP 输出通 量的贡献率最大, 均达到 $60 \%$ 以上; 污水来源的磷的贡献率是相对较低的,但是仍在 $35 \%$ 以上; AM 和 TG 情 景下污水来源的磷的贡献率都有所增加, 其中 AM 情景下增加到了 $43 \%$, TG 情景下增加到了 $55 \%$, 成为 DIP 输出通量的主要来源 (图 4b), 这说明, 在 TG 情景下, 一方面由于实行了技术革新措施, 有效提高了磷肥 和有机肥的利用率, 减少了非点源磷的流失量, 从而有效降低了输出的 DIP 通量; 另一方面, 随着人口增加 和经济发展, 产生的污水量逐年增加, 污水处理措施仅能去除污水中不到 $20 \%$ 的磷, 而且受到社会经济发 展、重视程度和人员素质等多种因素的影响, 新技术的开发、应用和推广需要较长的时间周期, 所以,相比较 其它三种情景, 虽然 TG 情景下的污水来源的磷输人通量是最低的, 但是相比之下 DIP 输出通量降低的更 多,所以污水来源的磷的贡献率相对较高.

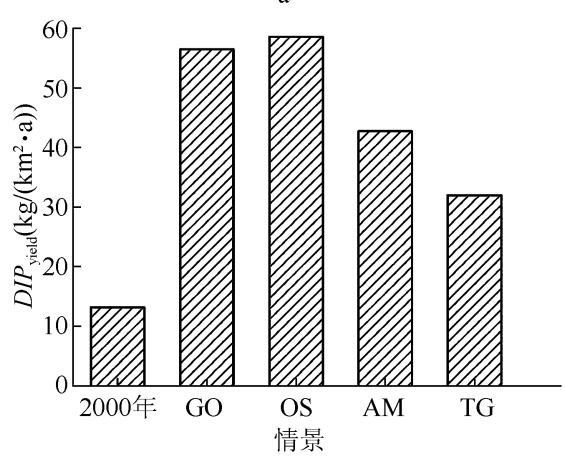

$\mathrm{b}$

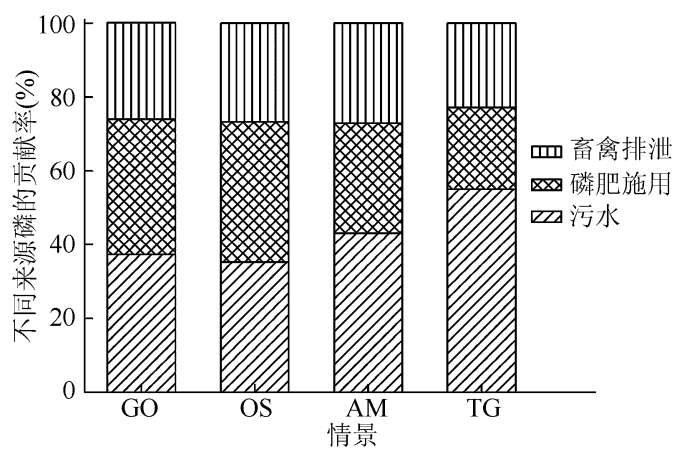

图 42050 年四种情景下的 DIP 输出通量 (a) 和不同来源磷的贡献率 (b)

Fig. 4 DIP yields(a) and contribution of different sources of phosphorus(b) under four scenarios in 2050 


\section{3 结论}

应用全球流域营养盐输出模型, 基于对人类活动影响河流营养盐输移的定量分析, 估算了 $1970-2003$ 年长江输出 DIP 的通量, 分析了其时间序列变化和不同来源的贡献率, 并基于 MEA 计划, 对 2050 年长江输 出 DIP 的通量进行了预测. 主要得出以下结论:

(1) DIP 输出通量呈波动增加的趋势, 在 1985 年以前, DIP 输出通量变化很小, 而在 1985 年以后, DIP 输出通量迅速增加, 2003 年达到了 $14.05 \mathrm{~kg} / \mathrm{km}^{2}$, 比 1970 年 $\left(2.45 \mathrm{~kg} / \mathrm{km}^{2}\right)$ 增加了接近 5 倍.

（2）在污染源中, 1985 年以前,污水是磷素输出的主要来源; 1985 年以后,污水的贡献率呈逐年下降的 趋势, 而磷肥施用的贡献率逐年增加, 1993 年以来已经超过了污水来源的磷的贡献率, 稳定在 $48.00 \%$ 左右, 成为 DIP 输出通量的主要来源; 畜禽粪便释放对于 DIP 输出通量的贡献率相对稳定,在 1986-2003 年间大 约在 $22.87 \%$ 左右.

（3）２０50 年无论何种情景下,长江输出的 DIP 通量都将超过 2000 年的水平 2 倍多,但是不同情景下 DIP 通量增加的幅度及污染源的贡献率有较大差别. 实行技术革新情景下,会有效减少非点源污染, 从而降 低长江输出的 DIP 通量.

\section{4 参考文献}

[ 1 ] Holligan PM, de Boois H. Land-Ocean Interactions in the Coastal Zone ( LOICZ) Science Plan. In: Turner RK ed. Global change report. Stockholm: IGBP, 1993, 25: 50.

[ 2 ] Syvitski JPM, Peckham SD, Hilberman R et al. Predicting the terrestrial flux of sediment to the global ocean: A planetary perspective. Sedimentary Geology, 2003, $162:$ 5-24.

[ 3 ] Seitzinger SP, Kroeze C. Global distribution of nitrous oxide production and N inputs in freshwater and coastal marine ecosystems. Global Biogeochemical Cycles, 1998, 12: 93-113.

[ 4 ] Leticia CC, Buitenhuis E, Quere CL et al. Potential impact of changes in river nutrient supply on global ocean biogeochemistry. Global Biogeochemical Cycles, 2007, 21 (doi:10. 1029/2006GB002718).

[ 5 ] Alexander RB, Johnes PJ, Boyer EW et al. A comparison of models for estimating the riverine export of nitrogen from large watersheds. Biogeochemistry, 2002, 57/58 : 295-339.

[ 6 ] Nixon SW. Coastal marine eutrophication: a definition, social causes, and future concerns. Ophelia, 1995, 41:199-219.

[ 7 ] Seitzinger SP, Harrison JA. Sources and delivery of carbon, nitrogen, and phosphorus to the coastal zone: An overview of Global Nutrient Export from Watersheds (NEWS) models and their application. Global Biogeochemical Cycles, 2005 , 19 ( doi:10. 1029/2005GB002606).

[ 8 ] 国家海洋信息中心. 中国海洋环境质量公报, 2000-2008 (http://www. coi. gov. cn/hygb/hjzl/2008/200902/ t20090220_6243. htm. ).

[ 9 ] Liu SM, Zhang J, Chen HT et al. Nutrients in the Changjiang and its tributaries. Biogeochemistry, 2003,62:1-18.

[10］胡明辉,杨逸萍,徐春林等. 长江口浮游植物生长的磷酸盐限制. 海洋学报, 1989,11(4):439-443.

[11］段水旺,章 申,陈喜保等. 长江下游氮、磷含量变化及其输送量的估计. 环境科学,2000,21:53-56.

[12] Duan SW, Liang T, Zhang S et al. Seasonal changes in nitrogen and phosphorus transport in the lower Changjiang River before the construction of the Three Gorges Dam. Estuarine, Coastal and Shelf Science, 2008, 79: 239-250.

[13] 沈志良. 长江磷和硅的输送通量. 地理学报,2006,61(7):741-751.

[14] Liu XC, Shen HT. Estimation of dissolved inorganic nutrient fluxes from the Changjiang River into estuary. Science in China (Ser B), 2001, 44 (Supplement) :135-141.

[15] 沈志良,古堂秀,谢肖勃. 长江生源要素的输出通量. 海洋科学, 1991,6:67-69.

[16］沈志良. 长江干流营养盐通量的初步研究. 海洋与湖沼,1997,28(5):522-528.

[17] Yao QZ, Yu ZG, Chen HT et al. Phosphorus transport and speciation in the Changjiang (Yangtze River) system. Applied Geochemistry, 2009, 24(11) : 2186-2194.

[18] Huang QH, Shen HT, Wang ZJ et al. Influences of natural and anthropogenic processes on the nitrogen and phosphorus fluxes of the Yangtze Estuary, China. Regional Environmental Change, 2006, 6(3) :125-131. 
[19] Yan WJ, Zhang S. The composition and bioavailability of phosphorus transport through the Changjiang (Yangtze) River during the 1998 flood. Biogeochemistry, 2003, 65: 179-194.

[20] Zhang J, Yan J, Zhang ZF. Chemical trend of national rivers in China: Huanghe and Changjiang. AMBIO, 1995, 24: 274 .

[21] Green PAC, Vorosmarty CJ, Meybeck M et al. Pre-industrial and contemporary fluxes of nitrogen through rivers: A global assessment based on topology. Biogeochemistry, 2004, 68: 71-105.

[22] Smith SV, Swaney DP, McManus LT et al. Humans, hydrology, and the distribution of inorganic nutrient loading to the ocean. Bioscience, 2003, 53(3): 235-245.

[23] Dumont E, Harrison JA, Kroeze C et al. Global distribution and sources of dissolved inorganic nitrogen export to the coastal zone: Results from a spatially explicit, global model. Global Biogeochemical Cycles, 2005, 19 ( doi : 10. 1029/ 2005GB002488).

[24] Caraco NF. Influence of human populations on P transfers to aquatic systems: a regional scale study using large rivers. In: Tiessen H ed. Phosphorus in the global environment: Transfers, cycles and management ( SCOPE 54). New York: Wiley, 1995 : 236-244.

[25] Harrison JA, Bouwman AF, Mayorga E et al. Magnitudes and sources of dissolved inorganic phosphorus inputs to surface fresh waters and the coastal zone: A new global model. Global Biogeochem Cycles, 2010, 24 ( doi: 10. 1029/ 2009GB003590).

[26] Global NEWS introduction (http://marine. rutgers. edu/globalnews/index. html. ).

[27］中华人民共和国国家统计局. 中国统计年鉴. 北京:中国统计出版社, 1980-2003.

[28] 湖北省统计局. 国家统计局湖北调查总队. 湖北统计年鉴. 北京: 中国统计出版社, 1980-2003.

[29] 湖南省统计局. 湖南统计年鉴. 北京: 中国统计出版社, 1980-2003.

[30］江西省统计局. 国家统计局江西调查总队. 江西统计年鉴. 北京: 中国统计出版社, 1980-2003.

[31 ] 重庆市统计局. 国家统计局重庆调查总队. 重庆统计年鉴. 北京: 中国统计出版社, 1997-2003.

[32] 四川省统计局. 国家统计局四川调查总队. 四川统计年鉴. 北京: 中国统计出版社, 1980-2003.

[33] 贵州省统计局. 国家统计局贵州调查总队. 贵州统计年鉴. 北京: 中国统计出版社, 1980-2003.

[34] 陕西省统计局. 国家统计局陕西调查总队. 陕西统计年鉴. 北京: 中国统计出版社, 1980-2003.

[35］云南省统计局. 国家统计局云南调查总队. 云南统计年鉴. 北京: 中国统计出版社, 1980-2003.

[36] 青海省统计局. 国家统计局青海调查总队. 青海统计年鉴. 北京: 中国统计出版社, 1980-2003.

[37] 安徽省统计局. 国家统计局安徽调查总队. 安徽统计年鉴. 北京: 中国统计出版社, 1980-2003.

[38 ] 河南省统计局. 国家统计局河南调查总队. 河南统计年鉴. 北京: 中国统计出版社, 1980-2003.

[39］甘肃年鉴编委会.甘肃年鉴. 北京:中国统计出版社,1980-2003.

[40］广西壮族自治区统计局. 广西统计年鉴. 北京:中国统计出版社, 1980-2003.

[41］西藏自治区统计局. 国家统计局西藏调查总队. 西藏统计年鉴. 北京: 中国统计出版社, 1980-2003.

［42］中华人民共和国农业部. 中国农业年鉴. 北京:中国农业出版社,1980-2003.

[43] 曾 悦,洪华生,陈伟琪等. 畜禽养殖区磷流失对水环境的影响及其防治措施. 农村生态环境, 2004,20(3):77-80.

[44] 中国农业大学. 家畜粪便学. 上海: 上海交通大学出版社, 1997.

[45] Yan WJ, Zhang S, Sun P et al. How do nitrogen inputs to the Changjiang basin impact the Changjiang River nitrate: A temporal analysis for 1968-1997. Global Biogeochem Cycles, 2003 , 17(4) : 1091 (doi: 10. 1029/2002GB002029).

[46] 中国水利部. 中国水资源公报. 1997-2003. Website: http://www. mwr. gov. cn/ztbd/zgszygb/index. asp.

[47] 国家水利部长江水利委员会. 长江年鉴. 武汉:《长江年鉴》编辑部, 1997-2003.

[48] 长江水利网 (http://www. cjw. gov. cn/index/cidian/cidian01. asp? link =4. ).

[49] 王佳宁,晏维金,贾晓栋. 长江流域点源氮磷营养盐的排放、模型及预测. 环境科学学报,2006,16(4):658-666.

[50] 王秀落, 李 楠, 任南琪等. 中国城市污水处理厂脱氮除磷工艺的应用与运行现状 (http://www. docin. com/ p-6178032. html. ).

[51] 污水两级生化处理除磷的探讨. 2007-11-8 (http://www. labbase. net/News/ShowNewsDetails-4-27-5BC794768F21073C. html. ).

[52］范业成. 江西磷肥肥效研究. 土壤肥料, 1991,3:18-22.

[53］全国农业技术推广服务中心. 中国有机养分资源. 北京: 中国农业出版社, 1994:256. 
[54] Seitzinger SP, Styles RV, Boyer EW et al. Nitrogen retention in rivers: model development and application to watersheds in the northeastern USA. Biogeochemistry, 2002, 57/58: 199-237.

[55] Burwell RE, Schuman GE, Heinemann HG et al. Nitrogen and phosphorus movement from agricultural watersheds. Journal of Soil and Water Conservation, 1997, 32: 226-230.

[56] McColl RHS, White E, Gibson AR. Phosphorus and nitrate runoff in hill pasture and forest catchments, Taita, New Zealand. New Zealand Journal of Marine and Freshwater Research, 1977, 11(4) : 729-744.

[57] Nicholaichuk W, Read DL. Nutrient runoff from fertilized and unfertilized fields in western Canada. Journal of Environmental Quality, 1978, 7 : 542-544.

[58 ] Sharpley AN, Syers JK. Phosphorus inputs into a stream draining an agricultural watershed: II . Amounts and relative significance of runoff types. Water Air Soil Pollution, 1979, 11: 417-428.

[59] Sharpley AN, Hedley MJ, Sibbesen E. Phosphorus transfers from terrestrial to aquatic ecosystems. In: Tiessen H ed. Phosphorus in the global environment: Transfers, cycles and management ( SCOPE 54). New York: Wiley, 1995: 171-199.

[60] Bennett EM, Carpenter SR, Caraco NF. Human impact on erodable phosphorus and eutrophication: A global perspective. Bioscience, 1999, 51(3) :227-234.

[61] Baker DB, Richards RP. Phosphorus budgets and riverine phosphorus export in northwestern Ohio watersheds. Journal of Environmental Quality, 2002, 31: 96-108.

[62］曹志洪,林先贵,封 克等.太湖流域土-水间的物质交换与水环境质量. 北京:科学出版社,2006:84.

[63 ] Harrison JA, Seitzinger SP, Bouwman AF et al. Dissolved inorganic phosphorus export to the coastal zone: Results from a spatially explicit, global model. Global Biogeochemical Cycles, 2005, 19(doi : 10. 1029/2004GB002357).

[64] 朱兆良.中国土壤氮素研究.土壤学报,2008,45(5):778-783.

[65］李世东,陈应发. 长江中上游防护林体系建设的若干思考. 林业经济, 1999,6:7-14.

[66] Schoumans OF, Goenendijk P. Modeling soil phosphorus levels and phosphorus leaching from agricultural land in the Netherlands. Journal of Environmental Quality, 2000, 29: 111-116.

[67］章明奎,周 翠, 方利平. 蔬菜地土壤磷饱和度及其对磷释放和水质的影响. 植物营养与肥料学报, 2006, 12 (4): 544-548.

[68 ] Zessner M, Gabriel O, Schilling CC et al. Outlines of a handbook for international nutrient balances on catchment scales, 14 including Minimum-Requirement-Data-List, Institute for water quality and wastemanagement, 15 Vienna University of Technology, Leibnitz Institute of freshwater ecology and inland fisheries, 16 Berlin; Institute of land and water management, Petzenkirchen; Institute for water pollution 17 control, Vituki Budapest. 2005.

[69] Bouwman AF, Drecht GV, Knoop JM et al. Exploring changes in river nitrogen export to the world's oceans. Global Biogeochemical Cycles, 2005, 19(doi:10. 1029/2004GB002314).

[70 ] Drecht GV, Bouwman AF, Harrison J et al. Global nitrogen and phosphate in urban waste water for the period 1970-2050. Global Biogeochemical Cycles, 2009, 23(4) (doi:10. 1029/2009GB003458). 